\title{
EXPERIÊNCIAS DE EDUCAÇÃO QUILOMBOLA: AS RELAÇÕES ENTRE ESCOLA E COMUNIDADE
}

\author{
Kalyla Maroun (UFRJ)* \\ Edileia Carvalho (PUC/RIO)**
}

\begin{abstract}
RESUMO
Este artigo objetiva comparar experiências de educação em duas comunidades quilombolas situadas na Região Sul-Fluminense, a partir das relações estabelecidas entre escola local e comunidade. A coleta de dados ocorreu entre os anos de $2011 \mathrm{e}$ 2017 e contou com: etnografia; entrevistas com as principais lideranças políticas das comunidades pesquisadas; análise de documentos oficiais disponíveis nas respectivas escolas e Secretarias Municipais de Educação. Percebemos que tais experiências, ainda que apresentem pontos em comum, podem ser tão diversas como os próprios processos de formação das comunidades. Pensar em experiências de educação escolar quilombola pressupõe nos abrirmos à pluralidade de possibilidades que estas representam.
\end{abstract}

Palavras-chave: Educação escolar quilombola. Escola. Comunidade quilombola.

\section{ABSTRACT \\ EDUCATION EXPERIENCE QUILOMBOLA: RELATIONS BETWEEN SCHOOL AND COMMUNITY}

This work aims compare two quilombola education experiences, from the observation of the relationship between school and community. Data collection took place between the years 2011 and 2017 and included: ethnography; interviews with political leaders of the two communities studied; analysis of official documents available in their schools and Municipal Departments of Education. We realize that such experiences, despite having common ground can be as diverse as the very processes of formation of communities. Think of quilombola school education experiences presupposes open ourselves to the countless possibilities they represent.

Keywords: Quilombola school education. School. Quilombola community.

\section{RESUMEN}

\section{EXPERIENCIAS DE EDUCACIÓN QUILOMBOLAS: LA RELACIÓN ENTRE LA ESCUELA Y LA COMUNIDAD}

Este artículo tiene como objetivo comparar las experiencias de educación en dos comunidades quilombolas ubicadas en la región del Sur Fluminense, a partir de las

* Doutora em Educação pela Pontifícia Universidade Católica do Rio de Janeiro (PUC/RIO). Professora Adjunta da Faculdade de Educação da Universidade Federal do Rio de Janeiro (UFRJ). Pesquisadora do Laboratório de Pesquisas em Educação do Corpo da Faculdade de Educação (LABEC/UFRJ). E-mail: kalylamaroun@gmail.com

** Doutoranda em Educação pela Pontifícia Universidade Católica do Rio de Janeiro (PUC/RIO). Educadora na ONG Novamerica. Membro do Grupo de Estudos em Culturas, Escola e Cotidiano da Faculdade de Educação (GECEC/PUC-RIO). E-mail: edileia.rj@hotmail.com 
relaciones que se establecen entre la escuela y la comunidad local. La recolección de datos se realizó entre los años de 2011 y 2015, e incluyó: la etnografía; entrevistas con los principales líderes políticos de las comunidades encuestadas; análisis de documentos oficiales disponibles en las respectivas escuelas y Secretarías de Educación Municipal. Notamos que dichas experiencias, a pesar de presentar puntos en común, pueden ser tan diversas como los propios procesos de formación de las comunidades. Pensar experiencias de educación escolar quilombolas requiere que nos abramos a la pluralidad de posibilidades que las mismas representan.

Palabras clave: Educación escolar quilombola. Escuela. Comunidad quilombola.

\section{Introdução}

As políticas de diversidade voltadas à educação conquistaram visibilidade dentro do espaço político-governamental ao longo das primeiras décadas do século XXI, a exemplo da Lei $n^{\circ} 10.639$, de 2003 (BRASIL, 2003) e suas respectivas Diretrizes Curriculares (BRASIL, 2004), que tornaram obrigatório o ensino da história e da cultura afro-brasileira e africana na educação básica. Citamos como outro exemplo de tais políticas as Diretrizes Curriculares Nacionais para a Educação Escolar Quilombola (BRASIL, 2012), nova modalidade de educação no Brasil. Estas iniciativas, em conjunto com outras ações e circunstâncias, ${ }^{1}$ contribuíram para a ampliação do debate político, social e acadêmico acerca da educação em comunidades quilombolas, legitimando a imersão de seus saberes, culturas e tradições nos currículos escolares.

Destacamos que, apesar da visibilidade obtida em governos anteriores, o contexto político que estamos vivenciando atualmente no Brasil parece apresentar um cenário cada vez menos favorável ao diálogo, o que pode vir a fragilizar a promoção das políticas educacionais voltadas à diversidade e/ou ao reconhecimento das diferenças, questão central no escopo deste trabalho.

As relações que podem ser estabelecidas entre educação e cultura(s) vêm adquirindo paulatinamente maior importância. As implicações políticas e epistemológicas desta relação (HALL, 1997)

1 Como a criação da Secretaria de Políticas de Promoção da Igualdade Racial (Seppir), em 2003, e da Secretaria de Educação Continuada, Alfabetização e Diversidade (Secad), em 2004, atual Secadi (Secretaria de Educação Continuada, Alfabetização, Diversidade e Inclusão), desde 2011. No ano de 2016, a Secadi é extinta, o que aponta para um cenário preocupante no que tange às políticas por ela geridas. podem ser percebidas no Brasil, sobretudo no âmbito das chamadas políticas educacionais voltadas às diversidades e/ou às diferenças. A busca pela construção de processos educativos culturalmente referenciados se intensifica, contribuindo para que diferentes atores sociais, políticos e acadêmicos assumam esse debate.

Nesse sentido, este trabalho objetiva analisar e comparar duas experiências de educação quilombola, a partir da observação das relações estabelecidas entre escola e comunidade em dois campos empíricos distintos. Para tanto, nos debruçamos sobre a história de formação, luta e resistência de duas comunidades situadas na Região Sul-Fluminense: Campinho da Independência (Paraty) e Santa Rita do Bracuí (Angra dos Reis), bem como sobre as relações estabelecidas entre estas e as escolas localizadas em seus territórios. A escolha de tais comunidades se justifica por duas questões. Primeiramente, percebemos no cenário estadual do Rio de Janeiro o destaque destas comunidades no movimento de luta por uma educação diferenciada junto aos seus respectivos municípios. Além disso, compreendemos que a experiência no campo da educação vivenciada pelas referidas comunidades aponta dilemas e estratégias singulares que nos auxiliam na reflexão sobre a pluralidade das emergentes demandas de educação escolar quilombola.

Para o acúmulo de dados empíricos utilizamos, ao longo do trabalho de campo, iniciado em 2011 e estendido até os dias atuais em razão do doutoramento de uma das autoras do presente trabalho, os seguintes procedimentos: etnografia; entrevistas com as principais lideranças políticas das duas comunidades pesquisadas; análise de documentos 
oficias disponíveis nas escolas e nas respectivas Secretarias Municipais de Educação. Predominaram nesta pesquisa as vertentes interpretativista e culturalista da etnografia de Geertz (1989), já que não há uma busca pelas leis e regras que regem as comunidades, mas pelo aspecto simbólico relacionado à cultura, ou seja, há uma descrição densa daquilo que foi observado. O foco, portanto, recai sobre os protagonistas desse processo, ainda em aberto, de construção de modelos de educação escolar quilombola, ou seja, partiremos das perspectivas encontradas no interior das comunidades pesquisadas.

\section{Breve histórico de formação das comunidades quilombolas pesquisadas}

Apresentaremos aqui um breve histórico dos processos de formação das duas comunidades quilombolas pesquisadas. A partir disso será possível percebermos aproximações e afastamentos entre os respectivos processos, isto é, questões mais gerais, que costumam se repetir entre os processos de formação de tais grupos étnicos, e especificidades, que apontam para o protagonismo e estratégias utilizados pelas comunidades. Esta apresentação é fundamental para a compreensão das experiências de educação quilombola nesses contextos. Abordaremos lutas que apontam não apenas para um processo de resistência, mas também para uma "aposta de (re)construção" de um sentido "coletivo de pertencimento e de ser" (WALSH, 2012, p. 68), que reverberam no campo educacional.

Campinho da Independência é o nome da primeira comunidade quilombola titulada no estado do Rio de Janeiro. No final do século XIX, com a decadência do regime escravocrata e com o processo de desagregação das propriedades da região, o "Senhor da Independência" (forma como era chamado o antigo fazendeiro escravista e proprietário do local) teria doado parte das suas terras a três escravas que viviam na casa grande da Fazenda Independência.

Campinho está localizado ao longo da costa litorânea do Rio de Janeiro, à margem da Rio-Santos, assim como Bracuí, e, por isso, sofreu os efeitos impostos pela abertura da rodovia, na década de
1970, que trouxe a supervalorização da área e, consequentemente, o surgimento da especulação imobiliária na região. Intensificou-se o interesse por empreendimentos turísticos e, como consequência, grande parte da população tradicional foi expulsa de suas terras. Os moradores passaram, então, a enfrentar uma acirrada disputa por suas terras e a conviver com ameaças de invasão de grileiros (aqueles que compras e vendem terras ilegalmente) e do Poder Público do estado do Rio de Janeiro, que diversas vezes tentou retirá-los da região.

A abertura da Rio-Santos impactou diretamente o modo de vida das populações tradicionais do local (LIMA, 2008). Campinho, que vivia da agricultura familiar, passou a ter no roçado uma prática de trabalho secundário. Grande parte dos moradores da comunidade passou a se encontrar na condição de trabalhador temporário no centro de Paraty, sem garantias trabalhistas e estabilidade (GUSMÃO, 1998).

No ano de 1975, organizados em torno da Comunidade Eclesial de Base (CEB) e com a ajuda da Comissão Pastoral da Terra (CPT), os moradores da comunidade entraram com ações individuais de usucapião, argumentando que desde o século XIX habitavam aquelas terras. Entretanto, os processos judiciais ficaram paralisados durante anos, assim como dispersos por diferentes cartórios.

Anos depois, ainda vivenciando um processo de luta e enfrentamentos em torno da posse da terra, em 1994, os quilombolas de Campinho fundaram a Associação de Moradores do Quilombo do Campinho (AMOQC) e começaram, então, a exigir a titulação coletiva de suas terras, tendo em vista a aplicação do Artigo 68 da Constituição Federal de $1988 .^{2}$

A titulação, porém, só ocorreu no dia 21 de março de 1999, quando a comunidade recebeu da Fundação Cultural Palmares (FCP) e da Secretaria de Assuntos Fundiários do Estado do Rio de Janeiro o título definitivo de seu território, tendo como outorgada a AMOQC. O reconhecimento oficial da comunidade como remanescente de quilombo levou à sua entrada no cardápio de políticas públicas oficiais e de iniciativas de organizações sociais, o

\footnotetext{
2 "Aos remanescentes das comunidades dos quilombos que estejam ocupando suas terras é reconhecida a propriedade definitiva, devendo o Estado emitir-lhes os títulos respectivos" (BRASIL, 1988).
} 
que produziu, por sua vez, uma enorme visibilidade da comunidade no contexto sociopolítico de Paraty, fato este que influenciou positivamente a comunidade de Bracuí em seu processo de reconhecimento e luta pelo território, como veremos adiante.

Com a titulação de suas terras no ano de 1999, a comunidade entra em um novo ciclo, com repercussão tanto sobre seu modo de vida, quanto sobre sua organização política. Desse contexto emergem novas lideranças, predominantemente jovens, afinadas com o discurso do movimento negro e com o do campesinato, mais escolarizadas e disponíveis a participarem das articulações políticas que marcam o início do movimento quilombola nacional. A partir desse período, iniciam-se também os projetos culturais e de desenvolvimento, que viabilizaram a construção da casa de artesanato, a implementação de um Ponto de Cultura, ${ }^{3}$ um programa de Turismo de Base Comunitária, um programa de valorização dos chamados Griôs ${ }^{4}$ e um projeto de agroecologia. Todo esse movimento coloca a comunidade em uma espécie de vanguarda da mobilização negra rural e, até mesmo, das comunidades tradicionais da região.

Os projetos e programas criados trouxeram conquistas cotidianas importantes para a comunidade, tais como o reavivamento de práticas de plantio, de trabalhos artesanais e do jongo enquanto elementos de pertencimento identitário. Além disso, permitiram a construção de uma autogestão do seu território, de sua produção e do seu próprio trabalho.

Percebemos que o reconhecimento da comunidade como remanescente de quilombo, bem como sua tomada de posição política em torno de uma identidade quilombola, impactou diretamente a vida dos moradores, sobretudo corroborou para um novo processo de organização político-comunitária num cenário de afirmação e resistências.

Nesse contexto, destacamos a mobilização e o protagonismo da AMOQC, por meio de suas lideranças políticas, no Fórum de Populações

3 Os Pontos de Cultura compreendem iniciativas culturais desenvolvidas pela sociedade civil que estão sendo potencializadas pelo Governo Federal, através do Programa Mais Cultura, em conjunto com os Governos Estaduais. Os recursos poderão ser utilizados para a realização de cursos e oficinas, produção de espetáculos e eventos culturais, compra de equipamentos, entre outros.

4 Os Griôs podem ser descritos como contadores de histórias, que têm como missão a valorização da cultura local através da tradição oral.
Tradicionais de Paraty, criado em julho de 2007, abarcando comunidades da região Sul do estado do Rio de Janeiro e da região Norte de São Paulo. $\mathrm{O}$ fórum constitui um importante instrumento para o reconhecimento dos direitos das populações tradicionais e para a implementação da Política Nacional de Desenvolvimento Sustentável dos Povos e Comunidades Tradicionais, conforme dispõe o Decreto $n^{\circ} 6.040$, de 7 de fevereiro de 2007 (BRASIL, 2007). O fórum trata de um espaço de fortalecimento e articulação política de comunidades quilombolas, indígenas e caiçaras de Angra dos Reis, Paraty e Ubatuba, espaço onde as comunidades se reúnem para discutir questões comuns, tais como: território, turismo, educação, cultura, pesca, agricultura, agroecologia, mercado solidário, dentre outras. Outro importante destaque a ser feito é a participação de duas lideranças da comunidade na Coordenação Nacional das Comunidades Quilombolas (CONAQ) no presente momento.

O despontar de uma nova organização política e social em Campinho significou, também, o começo dos primeiros embates entre a comunidade e a escola local. Embora já houvesse uma reflexão sobre a questão educacional, encaminhada, sobretudo, por uma liderança feminina da comunidade, Laura Maria dos Santos (nossa interlocutora neste traba1ho), foi a partir dessa nova organização política-comunitária que a associação começou a entender que a escola precisava entrar no debate sobre suas lutas identitárias. Sobre esse tema discorreremos mais adiante.

Santa Rita do Bracuí é uma comunidade quilombola situada em um município vizinho a Paraty, localizando-se em Angra dos Reis. Com a abolição da escravidão, os descendentes de escravos permaneceram nas terras da Fazenda Santa Rita, que foram doadas a eles pelo fazendeiro Comendador José de Souza Breves, por meio do seu testamento, no ano de 1877.

Falta consenso sobre dados quantitativos a respeito dessa população. Tanto o laudo como o relatório antropológico (BRAGATTO, 1999; MATTOS et al., 2009), sobre os quais nos debruçamos, não fornecem informações sobre o número de famílias que atualmente ocupam a área, tampouco sobre o tamanho do território, já que muitas terras foram perdidas devido a conflitos fundiários que 
vêm assolando a comunidade, como ocorreu com a comunidade vizinha de Campinho, em razão da especulação imobiliária. Muitas famílias foram pressionadas a abandonar ou vender suas terras, recebendo pequenas indenizações.

Mesmo com a doação formal antes do fim da escravidão, a comunidade vem lutando ainda nos dias de hoje pela titulação definitiva de suas terras. Entretanto, se a luta pela terra se inicia em Bracuí por meio da legislação que abarcava as comunidades rurais de uma forma geral (com assessoria do Sindicato dos Trabalhadores Rurais e da CPT), a partir do final da década de 1990, a categoria jurídica remanescente de quilombo, que resultou no surgimento de novos sujeitos políticos de direitos (ARRUTI, 1997), passa a ser utilizada pela comunidade como uma forma alternativa à resolução dos antigos conflitos fundiários, assim como ocorreu em Campinho.

O processo de autoatribuição enquanto comunidade remanescente de quilombo e de construção de sua respectiva identidade quilombola ocorreu em Bracuí mais tardiamente, se o compararmos com Campinho, e de forma cruzada a outro processo: o de reavivamento do jongo. ${ }^{5}$ Nosso interlocutor, Délcio Bernardo, educador popular, jongueiro e um dos fundadores do movimento negro de Angra dos Reis, que trabalha atualmente na Secretaria de Educação do município, conta que, em 1997, foi iniciado um debate em Bracuí em torno da utilização do Artigo 68 para a reivindicação das terras do seu respectivo território.

A FCP certificou a comunidade em 1999. Para tanto, como etapa concomitante e/ou posterior à certificação, foi realizado o laudo antropológico (BRAGATTO, 1999) de Bracuí. Este demonstrou o histórico de ocupação da terra a partir da permanência dos escravos na fazenda Santa Rita, após a morte de José de Souza Breves (1889), em posses familiares, com uma área de uso comum, onde ficavam equipamentos, tais como o engenho de cana e a engenhoca. Além disso, os elementos ressaltados pelo laudo sobre a apropriação do grupo na autoatribuição quilombola foram: a ancestralidade comum e a prática do jongo na tradicional

5 Para um aprofundamento sobre a relação do reavivamento do jongo com a construção e reafirmação identitária em Santa Rita do Bracuí sugerimos a leitura do trabalho de Maroun (2013). festa em homenagem à padroeira da comunidade, Santa Rita.

O ano de publicação do laudo antropológico de Bracuí coincidiu com o ano da titulação da comunidade vizinha de Campinho. Iniciou-se, a partir de então, uma aproximação e um diálogo entre as duas comunidades, o que trouxe uma referência para Bracuí sobre os próximos passos indispensáveis ao processo de titulação definitiva do seu território quilombola, após a certificação oferecida pela FCP. No entanto, o reconhecimento de Bracuí enquanto remanescente de quilombo, fato este que poderia representar a regularização das terras em nome da associação de moradores, até o momento, não resultou na conclusão exitosa do processo.

Entretanto, se inicialmente o diálogo com Campinho inseriu-os nos trâmites fundamentais para a reivindicação de suas terras como quilombolas, foi em razão da reafirmação de sua identidade jongueira que Bracuí iniciou a luta por seus direitos. $\mathrm{Na}$ fala de um dos integrantes da Associação dos Remanescentes de Quilombo de Santa Rita do Bracuí (Arquisabra): "Se nós somos quilombolas hoje é por causa de Campinho e do Délcio" (VALMIR, 2011). Nesse caso, ao mencionar o nome do Délcio, ele traz à tona o seu importante papel de mediação no reavivamento e na consolidação do jongo na comunidade. Além de ser um forte elemento de reafirmação identitária, o jongo também teve um papel fundamental na organização política de Bracuí. Em 2005, para a elaboração do projeto "Pelos Caminhos do Jongo", ${ }^{6}$ a necessidade de um diálogo interno maior e de uma organização política mais concisa começa a ficar evidente para os próprios moradores. Estes passaram a se reunir mais, a debater sobre as demandas do grupo, reconhecendo que, para terem acesso a determinadas políticas, precisavam se organizar no formato de uma associação de moradores. Na esteira da elaboração e da submissão do projeto "Pelos Caminhos do Jongo", a Arquisabra tem a sua primeira gestão registrada em cartório, ainda no ano de 2005. Dessa forma, podemos dizer que o movimento realizado em torno

6 O referido projeto, que tinha como objetivo oferecer oficinas de jongo para as crianças da comunidade, foi submetido e aprovado pela Brazil Foundation, uma organização não governamental que apoia iniciativas da sociedade civil brasileira que propõem soluções criativas e diferenciadas para os desafios enfrentados por comunidades de todo o País. 
do jongo reverberou em uma organização política imprescindível à luta pela titulação, haja vista que, regularizado o território, o título é registrado em nome da associação de moradores.

Junto ao processo descrito de reconhecimento positivo da identidade quilombola por meio do jongo, o que ocorreu, também, em razão das práticas educativas vinculadas a ele, quatro jovens quilombolas de Bracuí concluíram o curso de Licenciatura em Educação do Campo, da Universidade Federal Rural do Rio de Janeiro (UFRRJ). ${ }^{7}$ Eles fizeram parte da primeira turma do curso, iniciado no ano de 2010. A conclusão do curso por parte destes jovens parece impactar ainda mais a luta por políticas públicas diferenciadas, principalmente no tocante à educação e à escola local. Abordaremos adiante o protagonismo que a juventude vem assumindo em relação aos diálogos e às demandas sobre a escola localizada em seu território.

Diante do exposto até aqui, percebemos alguns pontos em comum entre os processos de formação das duas comunidades, dentre os quais destacamos: a resistência frente à pressão para o abandono de suas terras em razão da abertura da rodovia Rio-Santos; o protagonismo da juventude e das lideranças na organização política dos grupos, bem como no fortalecimento da luta pelo território, o que inclui a educação nesses contextos. Dentre as diferenças que singularizam cada um dos processos, apontamos para a condição privilegiada que a comunidade de Campinho possui, uma vez que a titulação do território ocorreu no ano de 1999 , quando Bracuí ainda recebia a certificação da FCP. Esta última comunidade passa a se organizar politicamente muito recentemente, o que é fortalecido a partir de 2005, quando é criada a Arquisabra, enquanto aquela já está na agenda de políticas públicas do governo e de organizações sociais e acadêmicas antes mesmo do ano de sua titulação.

7 Inicialmente, o curso foi aberto visando à formação de 60 jovens e adultos dos Projetos de Assentamento da Reforma Agrária criados pelo Incra para atuação nas escolas do campo. Considerando as demandas específicas dos grupos étnicos no que diz respeito às políticas educacionais e de desenvolvimento rural, foram abertas dez novas vagas para indígenas e quilombolas. A inserção de quilombolas e indígenas no curso implica em um conjunto de conteúdos e metodologias de ensino voltado aos debates em torno das especificidades destes grupos étnicos, representando a primeira experiência de formação de professores quilombolas e indígenas no estado do Rio de Janeiro.

\section{Escola/comunidade: as relações estabelecidas nos territórios}

Neste momento, nos voltaremos às relações estabelecidas entre escola e comunidade nos dois territórios pesquisados, buscando apontar para os marcos representativos de aproximações e afastamentos entre ambas ao longo do tempo. A partir disso, teremos subsídios para uma análise sobre os caminhos que a educação escolar quilombola vem tomando nos dois contextos apresentados. $\mathrm{O}$ olhar lançado aqui parte da etnografia realizada ao longo do trabalho de campo, sobretudo sob o viés dos protagonistas do processo, que ainda se encontra em curso, de demanda por uma educação escolar quilombola.

A Escola Municipal Campinho da Independência, situada dentro da comunidade de Campinho, foi construída em uma área cedida por um dos moradores e funciona desde o ano de 1980. Atualmente, atende alunos da Educação Infantil e do Ensino Fundamental até o $5^{\circ}$ ano. Segundo dados empíricos fornecidos pela atual diretora da escola, coletados ao longo do trabalho de campo, dos 162 alunos matriculados, aproximadamente 80 são quilombolas.

A escola do Campinho é classificada no censo escolar como quilombola. Entretanto, essa classificação é concebida apenas no âmbito do acesso a recursos financeiros diferenciados, como o Fundo de Manutenção e Desenvolvimento da Educação Básica e de Valorização dos Profissionais da Educação (Fundeb). Não há, ainda, iniciativas politico-pedagógicas concretas que visem contemplar as especificidades de uma educação escolar quilombola. Um exemplo disso é a própria forma com que a Secretaria de Educação de Paraty concebe a Escola do Campinho. Embora dentro de um território quilombola, a escola encontra-se subordinada à coordenação de Educação Rural de Paraty, que, por sua vez, não traz em seu projeto político pedagógico - aplicado de forma única a todas as escolas inseridas nesse contexto - as questões históricas, étnicas, políticas, sociais e culturais da população afro-brasileira, tampouco as especificidades das comunidades remanescentes de quilombo. Tanto a direção da escola, como a Secretaria Municipal de Educação insistem em enunciá-la como escola 
rural, afirmando não concordarem com o rótulo de escola quilombola, uma vez que tal classificação poderia gerar a exclusão das crianças não quilombolas que também compõem o quadro discente da escola.

Desse contexto emergem duas problemáticas. A primeira é que, dentro desse formato de gestão, a zona rural é concebida de forma homogênea. Não há, portanto, o reconhecimento da diversidade presente no campo, sequer das especificidades dos diferentes povos que vivem naquela região no tocante à educação escolar. Vale aqui lembrar que a cidade de Paraty constitui um mosaico étnico onde habitam quilombolas, caiçaras e indígenas guaranis. Tal constatação se dá a partir do momento em que percebemos que não há, por parte da Secretaria Municipal de Educação, qualquer iniciativa de trabalhar com as questões étnico-raciais, tampouco com a própria aplicação da Lei no 10.639/2003 (BRASIL, 2003), mesmo considerando a relevância disso pelo fato de a escola de Campinho estar inserida em um território étnico-racial. A segunda problemática é que nem mesmo as especificidades de uma escola rural são contempladas, uma vez que a escola rural exige metodologias diferenciadas, Projetos Políticos Pedagógicos específicos e práticas pedagógicas que privilegiem as construções sociais da vida no campo.

A relação da comunidade com a escola local é cercada por um histórico de conflitos e, ao que parece, o momento atual aponta para uma rejeição radical da comunidade ao modelo escolar disponível, como veremos posteriormente. $\mathrm{O}$ debate sobre uma educação escolar quilombola no Campinho emerge de um contexto de luta identitária representada pela demanda de um modelo educacional que contemple e legitime sua cultura local e seus modos de vida. Cabe aqui ressaltar que todo esse debate na comunidade se dá antes mesmo da publicação das Diretrizes Curriculares Nacionais para a Educação Escolar Quilombola (BRASIL, 2012). Um marco fundamental que começou a legitimar o debate sobre uma possível "escola quilombola", e uma tentativa de aproximação com a escola local, foi a implementação do Ponto de Cultura Manoel Martins, em 2005, já que este veio atrelado a múltiplas e diferenciadas possibilidades de práticas educativas. O que a princípio seriam oficinas ${ }^{8}$ realizadas nos espaços da comunidade, destinadas às crianças e aos jovens, com o objetivo de lhes criar referências identitárias, tornou-se um projeto pensado pela comunidade para ser experimentado na escola. No mesmo período em que se iniciam as oficinas, intensificam-se as reclamações dos professores da escola com relação ao interesse e rendimento das crianças nas atividades escolares. A interlocutora Laura, integrante da AMOQC desde então, que possui a função de mediar as questões relativas à escola perante a comunidade, afirma ter sido chamada pela direção inúmeras vezes para ouvir queixas sobre o comportamento das crianças:

Um dia me chamaram na escola e disseram: 'Olha, Laura, você precisa dar um jeito nessas crianças, elas só querem ficar falando de jongo o tempo todo, de tambor, das saias de chita... As professoras estão reclamando, não conseguem dar aula.' Agora você vê, o que pra elas era um problema, pra mim significa novas possibilidades, inclusive de trazer sentido aos conteúdos escolares. (LAURA, 2013).

A partir disso, Laura percebeu que a proposta do Ponto de Cultura poderia orientar não apenas novas possibilidades para o currículo, mas poderia servir de plataforma para a elaboração de um Projeto Político Pedagógico condizente com as especificidades da sua comunidade. Dessa forma, com o objetivo de tornar os conteúdos escolares mais significativos para os alunos, partindo da premissa de que o conhecimento local - ocultado e deslegitimado pela escola - destacava-se no contexto das oficinas, Laura escreveu, no ano de 2005, com o apoio de uma pedagoga que morava na região de Paraty, o Projeto "Educando com Arte", ${ }^{9}$ pensado para ser experimentado na escola local.

A entrada do projeto em 2005, bem como da própria comunidade no espaço escolar, uma vez que os protagonistas eram os educadores populares griôs, artesãos e lideranças políticas reconhecidos no quilombo como mestres -, enfrentou grande resistência por parte da direção e dos(as) próprios(as) professores(as). Eram muitas questões, a princípio niveladas por formalidades burocráticas (autoriza-

\footnotetext{
8 As oficinas realizadas eram: capoeira de angola, jongo, cerâmica artística, percussão, construção de tambores e cestaria.

9 O projeto "Educando com Arte" foi sistematizado e publicado em livro com o apoio da Unesco no ano de 2008.
} 
ção da Secretaria Municipal de Educação, ofícios para utilizar os espaços da escola etc.), mas, com o passar do tempo, as questões apresentadas vinham também de outras ordens e fatores (não aceitação do projeto, resistência àquele modelo de educação proposto). Nesse sentido, é importante entendermos que o "Educando com Arte" propunha inverter a lógica de hierarquização no qual o sistema escolar é pensado, colocando todos (professores, alunos, demais funcionários) numa posição horizontal, nas palavras de Laura, "no mesmo patamar". Nesse contexto, não havia quem soubesse mais e quem soubesse menos, havia saberes e conhecimentos diferenciados. Era a comunidade apropriando-se de um espaço que é seu, levando sua perspectiva de escola de matriz africana para dentro da escola regular/tradicional.

Laura lembra que a repercussão do projeto foi muito positiva, o destaque se deu, sobretudo, em relação às crianças que moravam na comunidade. "[...] um momento de fortalecimento, de autoestima, de orgulho de ser negro" (LAURA, 2013). Tratava-se da difusão do conhecimento que tinha como base os saberes próprios da comunidade (WALSH, 2011).

A partir da experiência com o "Educando com Arte", as lideranças passam a denunciar o distanciamento entre a cultura da criança quilombola e a cultura privilegiada na escola, o que remete ao que explicita Walsh (2011), ao trazer o contexto de luta dos povos afrodescendentes pelo reconhecimento dos seus direitos no campo da educação. Para a autora, esse reconhecimento pode ser traduzido da seguinte forma:

É o valor de ensinar sobre o que muitos anos nos ensinaram que não teria valor, os conhecimentos que não haviam nos dito que eram conhecimentos, a luta é voltar a esta forma de conhecimento, a esta maneira de entender a vida, de entender nossos próprios saberes como também envolver os processos educativos nesta nossa visão de história e conhecimento. (GARCÍA; WALSH, 2010 apud WALSH, 2011, p. 4).

Um ano depois da implementação do projeto, houve substituição na gestão da Secretaria de Educação de Paraty e o "Educando com Arte" foi retirado da escola por solicitação da própria direção escolar. Esta iniciativa foi tomada sem que ao menos fosse feito um comunicado à comunidade. Inicia-se um período marcado por grandes enfrentamentos, tanto com a escola, quanto com a Secretaria. Nas palavras de Laura:

Qual foi a nossa estratégia? Se distanciar. Eles nos distanciaram, eles nos tiraram e precisava desse distanciamento mesmo, para a gente lidar com isso, fazer a digestão disso, acabar com a raiva... Então esse distanciamento propiciou a gente desfazer essa releitura e hoje a gente tem uma outra proposta. (LAURA, 2013).

Recentemente, o fim desse distanciamento da comunidade com a escola até foi cogitado pelas lideranças, uma vez que a coordenação das escolas rurais de Paraty, no âmbito da Secretaria de Educação, passou a ser ocupada por alguém mais próximo da comunidade. Entretanto, o diálogo tão esperado não aconteceu. Hoje, a luta das lideranças por uma educação diferenciada permanece, mas por outros vieses e estratégias políticas. Campinho da Independência protagoniza essa luta junto ao Movimento de Povos Tradicionais, inclusive juntamente com a comunidade de Bracuí, mas busca caminhos diferentes para pleitear seus direitos no campo da educação. Por não verem possibilidade de diálogo com a gestão atual da Secretaria Municipal de Educação, que se coloca totalmente contrária aos pleitos da comunidade, o que inviabiliza ações e aproximações com a escola, as lideranças decidiram pensar uma escola comunitária, autônoma, só para as crianças do quilombo. Logo, decidiram pensar o seu modelo de educação fora da escola regular/tradicional, gerido pela própria comunidade. Ainda não se sabe se subvencionada pelo Estado, o que também poderia ser um processo complexo e exaustivo, ou não. Apesar disso, permanecem no movimento de luta pela educação quilombola juntamente com outras comunidades, ajudando na reflexão sobre estratégias, ações e políticas públicas.

Localiza-se no território quilombola de Santa Rita do Bracuí a Escola Municipal Áurea Pires da Gama, na estrada de Santa Rita, principal rua do quilombo, bem próxima à "pista" (categoria nativa que designa a rodovia Rio-Santos), oferecendo atualmente o Ensino Fundamental e a modalidade de Educação de Jovens e Adultos (EJA). 
Mesmo estando localizada no território quilombola, apenas no ano de 2105 ela foi classificada como escola quilombola, como veremos adiante. Mesmo compreendendo que a simples classificação atribuída pela direção escolar não "implique a existência de qualquer diferenciação na sua forma física, nos métodos pedagógicos, na sua gestão, na composição e formação dos seus professores, nos materiais didáticos utilizados" (ARRUTI, 2017, p. 119), entendemos que há um problema político e/ ou de desconhecimento por parte dos gestores no tocante à correta forma de classificar as escolas localizadas nesses territórios étnicos.

Construída no início da década de 1970, a partir da construção da Rio-Santos, a escola Municipal Áurea Pires da Gama recebe hoje um percentual pequeno de alunos oriundos do quilombo.

As questões colocadas até aqui nos fazem indagar acerca da situação da escola localizada no território de Bracuí, no intuito de refletir sobre a experiência de uma educação escolar quilombola, uma vez que há demanda das lideranças políticas por fazê-la, ainda que em meio a um contexto heterogêneo de alunos composto por nordestinos, indígenas, ${ }^{10}$ caiçaras e negros quilombolas e não quilombolas.

Apresentaremos alguns fatos que demonstram aproximações e afastamentos entre a escola Áurea Pires da Gama e a comunidade de Bracuí. Para tanto, nossa principal interlocutora é Marilda de Souza Francisco: liderança política da comunidade, ex-aluna, mãe de dois ex-alunos e, atualmente, funcionária pública da rede municipal de educação de Angra dos Reis, locada como zeladora na referida escola, desde a década de 1990.

A relação com a escola municipal localizada no território de Bracuí vem sendo um campo de disputa política desde o seu nascimento. Ao longo desses aproximadamente 40 anos de existência, houve uma longa gestão, que representou um bom momento de aproximação entre escola e comunidade. Esta se inicia no final da década de 1990, estendendo-se até quase o ano de 2005, e é lembrada com saudosismo por Marilda: "Quando a

10 Há uma aldeia indígena no território quilombola chamada de Guaranis do Bracuí. Estes chegaram na década de 1970 à comunidade, mediante os "progressos" e as expulsões advindas, na década de 1970, da construção da Rio-Santos.
Elisa entrou, a Elisa era uma pessoa festeira, então ela gostava de tá em contato com o povo daqui da comunidade" (MARILDA, 2011). A fala da Marilda demonstra a aproximação afetiva de Elisa, diretora da escola durante mais de uma década, com a comunidade. Desta aproximação, destacamos dois resultados relevantes: o livro Bracuí: suas lutas e história, escrito por alguns professores da escola, em parceria com a comunidade, que objetivou trazer para o currículo a rica história do povo de Bracuí; e a realização da feira "Frutos da Terra","1 que foi uma iniciativa da comunidade, respaldada pela direção da escola. A feira também traz um marco importante da entrada do jongo na escola, pois foi nela, cuja primeira edição ocorreu em 2003, que o jongo do Bracuí se apresentou pela primeira vez para a comunidade escolar.

Entretanto, ainda que o jongo tenha sido inserido na escola no ano de 2003, na gestão posterior à da diretora Elisa, iniciada no ano de 2005, há um distanciamento da escola com a comunidade, o que acaba por contribuir para a invisibilidade desta última no contexto escolar. O jongo e, consequentemente, a comunidade de Bracuí retornaram algumas vezes à escola, mas de forma superficial e folclorizada, apenas para contemplar as datas específicas que fazem alusão à cultura negra e para cumprir a agenda referente à Lei $n^{\circ}$ 10.639/03 (BRASIL, 2003), como se simplesmente chamar o jongo para a escola contemplasse tal política educacional.

Tais apontamentos demonstram que, se no período da gestão da Elisa havia indícios de um diálogo entre escola e comunidade, muito mais por uma afinidade afetiva e/ou política da diretora com o quilombo do que por uma implementação de uma política pública específica, até bem pouco tempo isso havia se perdido. No momento atual observamos que, passado o distanciamento, a

11 "Frutos da Terra" consiste em uma feira que leva os saberes quilombolas para serem expostos na escola. Vendem-se também frutas, artesanatos e pratos típicos. Ficava livre a cada quilombola interessado em participar, levar o que achasse mais conveniente. A primeira versão foi realizada em 2003. No ano seguinte, a feira foi realizada novamente, tendo uma representação massiva dos quilombolas. Entretanto, com a mudança da direção escolar entre os anos de 2004 e 2005 (sai a Elisa), o evento perdeu o protagonismo quilombola, pois começaram a criar temas para embasar a feira, iniciando-se, assim, um período de afastamento entre esta e a escola. A feira continua a acontecer anualmente, mas os temas propostos nem sempre têm afinidade com as demandas da comunidade. 
escola volta a se aproximar da comunidade, o que poderá estar respaldado pela política educacional específica existente, representada pelas Diretrizes Curriculares Nacionais para a Educação escolar Quilombola(BRASIL, 2012), e por uma Secretaria de Educação politicamente sensível ao contexto da luta do movimento quilombola da região.

O projeto "Pelos Caminhos do Jongo", iniciado em 2005 e extinto há alguns anos, que oferecia oficinas de jongo para crianças e jovens quilombolas, representou uma experiência sistematizada e significativa de educação quilombola para a comunidade. Enquanto nelas eles se autoafirmavam enquanto quilombolas, em um processo de construção e valorização identitária, na escola, as mesmas crianças negavam-se a se assumir enquanto tal, envergonhando-se de sua condição étnica. Marilda nos traz um relato interessante, que expressa essa situação: "Quando eles sabiam que aquela criança era daqui, eles começaram: 'Ah, seu quilombola!' Aí a criança chorava, se acabava de chorar: 'Ah, eu não sou quilombola não, ai, ai, ai'. Aí teve uma vez que a menina estava quase se acabando de chorar lá atrás" (MARILDA, 2011).

$\mathrm{O}$ exemplo acima demonstra que, mesmo o jongo tendo sido um elemento fundamental na afirmação identitária e no desenvolvimento da autoestima das crianças do quilombo do Bracuí, a escola não o reconheceu e, tampouco, valorizou-o. Como nos demonstra Kabelenge Munanga (2005), o fato de a escola Áurea Pires da Gama receber majoritariamente alunos não quilombolas não justifica a ausência de discussões e conteúdos curriculares relativos aos saberes étnicos de seu povo. Para o autor, a história e a memória da comunidade negra não interessam apenas aos alunos e alunas negras, mas também àqueles que possuem outras ascendências étnicas. Nesse sentido, a memória e a história não pertencem somente aos negros, ou seja, pertencem a todos, já que diferentes grupos contribuíram, cada um a seu modo, para a formação da riqueza social e econômica da identidade nacional.

No momento atual, tanto em razão das demandas colocadas pela comunidade, como pela reformulação de políticas no interior da própria Secretaria de Educação de Angra dos Reis, observamos que a direção da escola se volta para a comunidade, retomando um diálogo que havia ficado em suspenso desde o fim da gestão da diretora Elisa, em 2005. O momento é propício para o debate sobre o quê, de fato, seria uma educação escolar quilombola.

No dia 12 de agosto de 2015 acompanhamos uma reunião realizada na escola Áurea Pires da Gama, que contou com a presença de lideranças da Arquisabra (no caso, os quatro jovens que concluíram o curso de Educação do Campo, e a Marilda), gestores da Secretaria de Educação de Angra dos Reis, professores da UFRRJ e da Universidade Federal Fluminense (UFF), que possuem trabalhos de extensão na comunidade, o corpo docente e a direção da escola. A razão do encontro era a decisão coletiva sobre a classificação da escola no censo escolar, isto é, se a escola atenderia à demanda da comunidade de classificá-la como quilombola ou não. As lideranças apresentaram suas posições junto à secretaria e à direção da escola para, em seguida, ocorrer a votação. Após muitos embates e estranhamentos por parte de alguns professores sobre a demanda apresentada que, por falta de oportunidade, não convém trazermos aqui, ficou decidido que a escola seria classificada como quilombola, com apenas um voto de abstenção e nenhum contra. Todos os presentes tiveram direito a voto, inclusive as lideranças quilombolas.

Diante da conjuntura apresentada, percebemos que tanto Campinho como Bracuí puderam vivenciar experiências educacionais muito significativas por meio dos Pontos de Cultura implementados nas comunidades. Eles foram relevantes na medida em que consistiram em sistematizações e práticas educativas pensadas e geridas a partir dos próprios quilombolas, contribuindo, também, para subsidiar as respectivas demandas de uma educação escolar diferenciada para seu povo. Entretanto, devido às especificidades e às questões políticas que assolam cada uma delas, as estratégias adotadas para a permanência na luta por uma educação quilombola que, de fato, lhes é um direito, trilha caminhos diferenciados atualmente.

\section{Uma análise comparativa das duas demandas apresentadas}

É interessante observarmos que o protagonismo político das comunidades apresentadas, 
principalmente no âmbito da luta por uma escola quilombola, ao mesmo tempo em que apresenta determinadas similaridades, o que chamamos aqui de pontos em comum, também traz consigo estratégias diferenciadas, em razão de suas respectivas histórias e demandas que, no entanto, assumem como objetivo comum a reivindicação por uma educação escolar condizente com suas culturas, seus costumes e seus saberes tradicionais. Tal observação nos leva a refletir sobre as constantes ressignificações que se apresentam na construção e implementação da educação escolar quilombola, por parte dos próprios sujeitos do processo, bem como acerca das estratégias políticas assumidas em cada um dos casos aqui trazidos.

Um dos aspectos observados em ambos os casos, e que desponta como desafio para a construção e implementação de educação escolar quilombola, é a pluralidade do público atendido nas escolas situadas em territórios remanescentes de quilombo. Tanto a escola do Campinho quanto a escola do Bracuí recebem alunos pertencentes a outros contextos étnicos e socioculturais. Toda essa pluralidade chama atenção para a forma como as diferenças são tratadas e concebidas no espaço escolar, para a maneira como a cultura, as identidades e as especificidades do território quilombola se apresentam e são, ou não, incorporadas na/pela escola, bem como para a forma como dialogam ou não com a diversidade existente. Nas palavras de Arruti (2017, p. 119):

'Escolas em áreas de quilombo' podem não receber apenas (e, eventualmente, nem mesmo principalmente) as crianças de tais comunidades, recebendo também crianças de comunidades do entorno. Da mesma forma, escolas situadas fora das áreas de quilombo, mas nas vizinhanças de comunidades quilombolas, podem atender também - e, por vezes, principalmente - as crianças dessas comunidades.

Compreendemos aqui que toda essa diversidade cultural poderia ser concebida como uma vantagem pedagógica (CANDAU, 2011 apud FERREIRO, 2001), ou seja, as diferenças poderiam ser vistas como intrínsecas aos processos pedagógicos, potencializando-os e tornando-os mais significativos, na medida em que as identidades seriam reconhecidas e valorizadas. Ocorre que os cenários ilustrados apontam para outra direção: embora situadas em territórios quilombolas e classificadas como tal, constatamos o posicionamento contrário à implementação destas sob o argumento da heterogeneidade do público atendido.

[...] A escola mudou, logo, a relação com a comunidade, com a cultura daqui, também tinha que mudar. Não temos só alunos quilombolas aqui. Aliás, a maioria não é quilombola. Hoje a demanda é outra. (PROFESSORA DE PORTUGUÊS DA ESCOLA ÁUREA PIRES DA GAMA, 2015).

Da afirmação acima emergem algumas questões importantes, dentre as quais destacamos a ausência de uma reflexão acerca da importância do debate étnico-racial e territorial, logo, do pertencimento a uma identidade étnica (BARTH, 2000), para a educação escolar quilombola, isto é, para as crianças e jovens quilombolas em idade escolar.

A defesa de uma "escola para todos" coloca em pauta o discurso da igualdade/universalidade que supõe um processo de homogeneização cultural, cuja educação escolar exerceu/exerce um papel fundamental, tendo por função difundir e consolidar uma cultura comum de base eurocêntrica, silenciando ou invisibilizando vozes, saberes, cores, crenças e sensibilidades (CANDAU, 2011). Da mesma forma, a justificativa que explica a negação de uma proposta de escola quilombola pautada no quantitativo de alunos atendidos pressupõe a perpetuação do silenciamento de uma identidade negada e invisibilizada histórica e socialmente. Nesse sentido, é interessante observarmos a lógica de pensamento das lideranças que estão mediando as lutas pela educação em suas comunidades.

A escola insiste em afirmar que essa escola não pode ser quilombola porque atende mais alunos de fora do que quilombolas. Eles não entendem... Essa escola é cem por cento quilombola. Todas as crianças moradoras da comunidade, atendidas pelos segmentos que a escola oferece, estão nessa escola, então ela é cem por cento quilombola, entende? (LAURA, 2014).

A fala da Laura, além de revelar a exclusão da identidade quilombola na escola, bem como as muitas relações de poder ali estabelecidas, denota também uma rejeição ao que a própria política de educação escolar quilombola determina à escola: 
III - reconhecer a história e a cultura afro-brasileira como elementos estruturantes do processo civilizatório nacional, considerando as mudanças, as recriações e as ressignificações históricas e socioculturais que estruturam as concepções de vida dos afro-brasileiros na diáspora africana; IV - promover o fortalecimento da identidade étnico-racial, da história e cultura afro-brasileira e africana ressignificada, recriada e reterritorializada nos territórios quilombolas; V - garantir as discussões sobre a identidade, a cultura e a linguagem, como importantes eixos norteadores do currículo. (BRASIL, 2012).

Desse modo, parece predominar a ideia de que as questões sobre a cultura negra e quilombola só interessam a quem é negro e/ou quilombola. Um instrumento de negação ao tratar das questões de cunho étnico-racial no contexto de práticas educativas. Do ponto de vista do nosso referencial teórico, ousamos salientar que tal fato representa um racismo epistêmico contra todas e quaisquer outras formas de culturas e de saberes que não sejam a ocidental, privilegiada histórica e socialmente, que tende a deslegitimar todo projeto que proponha uma "diversalidade epistêmica" (OLIVEIRA, 2010, p. 285).

Diante do exposto até aqui, indagamos: como ficaria, então, a Educação Escolar Quilombola no campo das especificidades que suas respectivas diretrizes curriculares mencionam? O que muitos podem conceber como uma demanda social incoerente - uma escola de fato quilombola, não apenas no tocante ao reconhecimento representado pela classificação perante o censo escolar, mas também com referências às suas especificidades -, pelo fato de existir em escolas quilombolas alunos não quilombolas, é reconhecido pelo Estado como um direito: dar atendimento diferenciado a essa população, tal como ocorre com a população indígena e os povos do campo, promovendo uma interlocução com esses dois campos, a fim de respaldar ações para uma escola quilombola diferenciada (ARRUTI, 2009).

Ainda segundo Arruti (2017), uma análise possível para a chamada educação quilombola se apresenta por meio do complexo campo da educação diferenciada, representada por entraves políticos que se dão não apenas no âmbito da sua regularização, ou seja, classificação, mas também nos contextos pedagógico e curricular, que devem estar pautados nos saberes e fazeres quilombolas, tanto no contexto das escolas localizadas nos referidos territórios étnicos, como naquelas que atendem alunos oriundos destes.

Uma questão que se apresenta de forma bastante interessante nesse contexto de análise são as estratégias incorporadas pelas comunidades no tocante à luta pela educação quilombola, mediante as relações estabelecidas com suas escolas locais e suas respectivas secretarias de educação.

Enquanto Bracuí inicia uma agenda de trabalho com a escola para pensar o processo de construção de uma escola, de fato, quilombola, não apenas no tocante à classificação perante o censo escolar, Campinho da Independência, diante da dificuldade em dialogar com a escola e com a atual coordenação da Secretaria de Educação de Paraty, distancia-se. É por entenderem a não viabilidade de suas lutas políticas dentro do contexto da escola que suas discussões sobre a educação quilombola permaneceram durante um longo período sem articulação com a escola.

O caminho trilhado estrategicamente por ambas as comunidades desponta para algumas questões importantes. No caso de Bracuí, por meio de suas jovens lideranças políticas, que tiveram/estão tendo acesso ao curso de Licenciatura em Educação do Campo na UFRRJ, inaugura-se um novo ciclo de relação com a escola local. Neste, incorporam-se, em suas reivindicações, a implementação das Diretrizes Curriculares Nacionais para a Educação Escolar Quilombola, compreendendo a educação escolar quilombola enquanto modalidade de ensino da educação básica. Ressaltamos que tais discussões eram, até então, desconhecidas pelos professores e pela própria direção da escola. É, portanto, por uma demanda apresentada pela própria comunidade que a escola passa a ser classificada como escola quilombola no censo escolar de 2015.

Em relação à construção dessa escola quilombola, as jovens lideranças começam a pressionar a escola para que viabilize a formação continuada para o corpo docente, com ênfase na temática quilombola, tendo como principais articuladores de tal formação as próprias lideranças. Para tanto, contam com a parceria de professoras do departamento de educação das universidades UFRRJ e UFF (campus 
de Angra dos Reis), bem como com pesquisadores parceiros da comunidade e movimentos sociais do município. Dessa forma, podemos observar que, apesar da classificação da escola como quilombola não significar literalmente uma mudança no seu fazer pedagógico, bem como no seu currículo, a atual gestão, tanto da escola quanto da Secretaria de Educação de Angra, entendem que este avanço exige um comprometimento político-pedagógico de todos os envolvidos.

Não queremos pensar apenas a classificação, mas pensar para além do Censo. Vocês estão dispostos a encarar essa proposta de uma escola nova? A continuar essa discussão para além dos muros da escola? O novo não está pronto, será construído! (SECRETÁRIA DE EDUCAÇÃO DE ANGRA, 2015).

Institui-se, portanto, em Bracuí, um momento favorável para o estreitamento dos laços entre escola e comunidade. Mesmo com toda dificuldade apresentada e com alguns entraves que surgem nesse processo de reaproximação (como a resistência de alguns professores), a comunidade, juntamente com a escola, vem pensando o que seria a educação escolar quilombola naquele contexto, de que maneira poderiam (re)pensar o Projeto Político Pedagógico norteador de suas práticas educativas e do currículo, dentre tantas outras questões que competem ao sistema escolar.

No caso de Campinho, a estratégia política assumida na luta por educação escolar que contemple sua cultura quilombola tem sido a articulação com outros movimentos sociais, como caiçaras e indígenas, no intuito de pensarem coletivamente um projeto de educação diferenciada, de enfoque basicamente comunitário (voltado aos interesses de cada etnia e/ou comunidade) e centrado na ideia da especificidade (histórica, cultural, linguística) dos grupos envolvidos. Cabe aqui ressaltar que Bracuí também participa dessa articulação, entretanto, vive em Angra dos Reis um momento bem diferente do estabelecido no cenário educacional do município de Paraty, local onde se encontram grande parte dos grupos representados pelo Fórum de Populações Tradicionais.

Outra significativa estratégia em Campinho é a formação de um Grupo de Trabalho (GT) específico para a discussão da educação quilombola, independente da educação formal. Tal iniciativa foi tomada diante da dificuldade que as lideranças encontravam no diálogo com o poder público local. O GT é formado por lideranças da comunidade, universidades, além de militantes de outros grupos (pesquisadores(as), ONGs, educadores(as) locais etc.).

É interessante pensarmos que a experiência atual vivenciada por Bracuí, de reaproximação com a escola, vem impactando Campinho, o que pode ser observado pela recente decisão de retomar o diálogo com a escola local e com a Secretaria Municipal de Educação. Para isso, a comunidade lança mão da produção de conhecimento oriunda do GT acima mencionado tanto para a reaproximação com o poder público local, quanto para pensar os possíveis caminhos para a construção do diálogo entre os dois espaços epistemológicos: a comunidade e a escola. Temos, assim, um novo ciclo no histórico de luta pela escola local, mas dessa vez a comunidade assume em sua pauta de discussão a situação da escola situada no quilombo de Cabral, ${ }^{12}$ localizado também no município de Paraty, a poucos quilômetros do quilombo do Campinho.

$\mathrm{O}$ esforço neste momento, que por ser muito recente ainda não pode ser analisado aqui, é de diálogo entre Secretaria Municipal de Educação, comunidade, e demais atores sociais que compõem o GT, para a reflexão sobre a reorientação curricular para as escolas quilombolas do município, tendo como parâmetro as Diretrizes Curriculares Nacionais para a Educação Escolar Quilombola, a exemplo do trabalho que vem sendo feito com as escolas caiçaras do local. ${ }^{13}$

Toda essa vivência das comunidades junto às escolas situadas em seus territórios, inclusive as especificidades que se apresentam nesse contexto de luta, nos remete à discussão trazida por Arroyo

12 A proposta de reorientação curricular que está em pauta neste momento, em que comunidade e Secretaria Municipal de Educação (SME) de Paraty tentam uma nova aproximação, irá contemplar as duas comunidades quilombolas existentes no município: Campinho e Cabral. A escola do Cabral é uma escola municipal que atende aos anos iniciais do Ensino Regular Fundamental. Está subordinada à coordenação das escolas rurais da SME de Paraty e funciona no sistema multisseriado.

13 A SME de Paraty, em parceria com o Colégio Pedro II e a UFF campus Angra, iniciou desde 2016 um trabalho de reorientação curricular das escolas caiçaras, conhecidas como as escolas costeiras, no intuito de agregar na grade curricular dessas escolas os saberes oriundos da comunidade local, da cultura caiçara. 
(2012). Para o autor, grupos como as comunidades quilombolas, ao se afirmarem sujeitos de saberes próprios, de outros processos de aprendizagem e experiências, de formação, de conscientização política e cultural, passam a resistir a esse modelo educacional hegemônico predominante, sobre o qual a instituição escolar ainda está fundamentada. Isso ocorre justamente porque eles se afirmam por meio de suas diferenças. Diferenças estas que também precisam ser consideradas quando pensamos a própria formulação de políticas direcionadas a essa população.

As questões trazidas no delinear dos cenários apresentados denotam processos de reinterpretações do que seria a chamada escola quilombola, estimuladas e/ou (re)orientadas pela própria relação que vai se constituindo e se modificando entre escola e comunidade. Um movimento de idas e vindas, de avanços e retrocessos, de diálogo e de silenciamento. Da mesma forma, ilustram como as experiências se entrecruzam, gerando novos contornos aos meandros das relações estabelecidas, ressignificando as estratégias de luta, trazendo diferentes atores sociais para o diálogo e abrindo novas possibilidades para mover-se e atuar nas brechas. Este "espaço ou lugar a partir do qual a ação, a militância, resistência, insurgência e transgressão são impulsionadas, onde as alianças se constroem, e surge um modo-outro que se inventa, cria e constrói" (WALSH, 2016, p. 72).

Nesse sentido, compreendemos que este movimento "não vem de cima, mas de baixo, das margens e das fronteiras, das pessoas das comunidades, dos movimentos" (WALSH, 2016, p. 72). Como afirma Laura, liderança do Campinho, "às vezes é preciso recuar, lançar mão de estratégias diferentes, se fortalecer na fortaleza da nossa própria construção [...]" (LAURA, 2014).

\section{Considerações finais}

Percebemos que o reconhecimento da diferença, cada vez mais evidente pela centralidade da cultura, tanto nas reflexões teóricas quanto na formulação das políticas educacionais, representa um grande desafio, mas também um importante impacto no cenário educacional na contemporaneidade. A proposta de uma escola quilombola pode contri- buir para o rompimento de uma lógica ocidental, monocultural e branca de escola na medida em que interroga o sistema escolar com a presença e a história de sujeitos outros, questiona suas práticas pedagógicas e as relações de poder ali constituídas.

Embora a educação escolar quilombola seja uma categoria recente, ainda em disputa pelos principais atores sociais envolvidos, percebemos, por parte das comunidades, novas reinterpretações da política educacional e demandas diversas por uma educação diferenciada. Nesse sentido, a elaboração de políticas específicas para esta modalidade de educação representa um aprendizado em processo, tanto para os quilombolas quanto para os gestores e professores. Já no que remete a alguns municípios e suas respectivas Secretarias de Educação, destacamos certo descomprometimento com a política educacional já existente e que embasa a reivindicação de comunidades quilombolas por um projeto outro de educação e de escola, a exemplo do que vem acontecendo no município de Paraty.

Uma questão interessante a pensar é o quanto a experiência do quilombo Santa Rita do Bracuí vai impactar na luta do quilombo Campinho da Independência, levando as lideranças locais a repensarem suas estratégias e caminhos trilhados para retomarem o diálogo com a Secretaria Municipal de Educação de Paraty e a vislumbrarem novamente a escola como um lugar de atuação, existência, criação e pensamento outro.

Outro aspecto que sobressai nos dois cenários analisados é o dilema vivido por ambas as comunidades. Enquanto Campinho retoma a tentativa de diálogo com o poder público local, reiniciando um novo ciclo de luta pela escola, na esperança de poderem respirar novos ares nessa relação silenciada entre escola e comunidade, Bracuí teme que todo esse processo já iniciado se perca e/ou retroceda mediante a entrada de uma nova gestão, desfavorável ao diálogo com a comunidade. Isso demonstra o quanto é frágil e limitada a política, uma vez que os sujeitos do processo estão sempre sujeitados à gestão municipal, a uma certa "boa vontade", bem como ao posicionamento político de suas respectivas escolas e secretarias de educação.

Em suma, a tentativa aqui foi apresentar possibilidades diferenciadas de experiências de educação quilombola, pelo olhar dos protagonismos desse 
processo, e das relações colocadas entre estes, suas respectivas escolas e secretarias. Desse modo, tais experiências, ainda que apresentem pontos em comum, podem ser tão diversas como os próprios processos de formação das comunidades. Pensar em experiências de educação escolar quilombola pressupõe nos abrirmos à pluralidade de possibilidades que estas representam.

\section{REFERÊNCIAS}

ARROYO, Miguel G. Outros sujeitos, outras pedagogias. Petrópolis, RJ: Vozes, 2012.

ARRUTI, José Maurício. A emergência dos “remanescentes”. Notas para o diálogo entre indígenas e quilombolas. Mana, Rio de Janeiro, v. 3, n. 2, p. 7-38, 1997.

. Políticas públicas para quilombos: terra, educação e saúde. In: PAULA, Marilene de; HERINGER, Rosana (Org.). Caminhos convergentes: Estado e sociedade na superação das desigualdades raciais no Brasil. Rio de Janeiro: Fundação Heinrich Boll/ActionAid, 2009. p. 75-110.

Conceitos, normas e números: uma introdução à educação escolar quilombola. Revista Contemporânea de Educação, v. 12, n. 23, p. 107-142, 2017.

BARTH, Fredrik. Os grupos étnicos e suas fronteiras. In: LASK, Tomke (Org.). O guru, o iniciador e outras variações antropológicas. Rio de Janeiro: Contra-Capa, 2000. p. 25-67.

BRAGATTO, Sandra. Laudo antropológico da Comunidade Remanescente de Quilombo de Santa Rita do Bracuhy. Parecer no004/FCP/MinC. Brasília, DF, 1999.

BRASIL. Presidência da República. Casa Civil. Constituição da República Federativa do Brasil de 1988. Brasília, DF, 1988. Disponível em: <http://www.planalto.gov.br/ccivil_03/constituicao/constituicao.htm>. Acesso em: 02 mar. 2017.

Presidência da República. Casa Civil. Lei no 10.639, de 09 de janeiro de 2003. Altera a Lei no 9.394, de 20 de dezembro de 1996, que estabelece as diretrizes e bases da educação nacional, para incluir no currículo oficial da Rede de Ensino a obrigatoriedade da temática "História e Cultura Afro-Brasileira", e dá outras providências. Brasília, DF, 2003b. Disponível em: <http://www.planalto.gov.br/ccivil_03/leis/2003/L10.639.htm>. Acesso em: 05 mar. 2017.

. Resolução CNE/CEB no 1, de 17 de junho de 2004. Institui Diretrizes Curriculares Nacionais para a Educação das Relações Étnico-Raciais e para o Ensino de História e Cultura Afro-Brasileira e Africana. Brasília, DF, 2004.

Presidência da República. Casa Civil. Decreto no 6.040, de 7 de fevereiro de 2007. Institui a Política Nacional de Desenvolvimento Sustentável dos Povos e Comunidades Tradicionais. Brasília, DF, 2007. Disponível em: <http://www.planalto.gov.br/ccivil_03/_ato2007-2010/2007/Decreto/D6040.htm>. Acesso em: 15 mar. 2017.

. Resolução CNE/CEB no 8, de 20 de novembro de 2012. Define Diretrizes Curriculares Nacionais para a Educação Escolar Quilombola na Educação Básica. Brasília, DF, 2012.

CANDAU, Vera Maria. Diferenças culturais, cotidiano escolar e práticas pedagógicas. Currículo Sem Fronteiras, v. 11, n. 2, p. 240-255, 2011.

FERREIRO, Emília. Cultura escrita e educação: conversas de Emilia Ferreiro com José Antonio Castorina, Daniel Goldin e Rosa María Torres. Tradução de Ernani Rosa. Porto Alegre: Artmed, 2001.

GEERTZ, Clifford. A interpretação das culturas. Rio de Janeiro: Guanabara Koogan, 1989.

GUSMÃO, Neusa Maria Mendes de. Projeto Mapeamento e Sistematização das Áreas Remanescentes de Quilombos: relatório técnico-científico da comunidade negra de Campinho da Independência, Paraty, RJ. Universidade Estadual de Campinas/FCP/UFA, 1998.

HALL, Stuart. A identidade cultural na pós-modernidade. Rio de Janeiro: DP\&A, 1997.

LIMA. Livia Ribeiro. Quilombos e políticas de reconhecimento: o caso do Campinho da Independência. 2008. 174 f. Dissertação (Mestrado em Antropologia Social) - Programa de Pós-Graduação em Antropologia Social da Universidade de São Paulo (USP), São Paulo, 2008. 
MATTOS, Hebe. Et al. Relatório antropológico de caracterização histórica, econômica e sociocultural do quilombo de Santa Rita do Bracuí. Niterói, RJ: INCRA/SRRJ/UFF/FEC, 2009.

MAROUN, Kalyla. Jongo e educação: a construção de uma identidade quilombola a partir de saberes étnico-culturais do corpo. 2013. 210 f. Tese (Doutorado em Educação) - Programa de Pós-Graduação em Educação da Pontifícia Universidade Católica do Rio de Janeiro (PUC-RIO), Rio de Janeiro, 2013.

MUNANGA, Kabengele (Org.). Superando o racismo na escola. Brasília, DF: Ministério da Educação/Secretaria de Educação Continuada, 2005.

OLIVEIRA, Luiz Fernandes. História da África e dos africanos na escola: as perspectivas para a formação dos professores de história quando a diferença se torna obrigatoriedade curricular. 2010. $274 \mathrm{f}$. Tese (Doutorado em Educação) - Programa de Pós-Graduação em Educação da Pontifícia Universidade Católica do Rio de Janeiro (PUC-RIO), Rio de Janeiro, 2010.

WALSH, Catherine. Etnoeducación e interculturalidad en perspectiva decolonial. In: SEMINARIO INTERNACIONAL ETNOEDUCACION E INTERCULTURALIDAD, 4., 2011, Lima, Perú. Anais... Lima, Perú: CEDET, 2011.

. Interculturalidad crítica y (de) colonialidad: ensayos desde Abya Yala. Quito: Ediciones Abya-Yala, 2012.

. Notas pedagógicas a partir das brechas decoloniais. In: CANDAU, Vera Maria (Org.). Interculturalizar, descolonizar, democratizar: uma educação “outra”? Rio de Janeiro: 7 Letras, 2016. p. 64-75.

Recebido em: 28/04/2017

Aprovado em: 28/06/2017 